\title{
MOBILE PHONE USES AND ITS EFFECT ON MENTAL HEALTH
}

\section{PROF. GIRIRAJ PRASAD SONI ${ }^{1}$, MR. OMPRAKASH SWAMI ${ }^{2}$}

${ }^{1}$ Dean \& Principal, Mahatma Gandhi Nursing College (MGUMST), Sitapura, Jaipur

${ }^{2}$ Asso. Prof. (Ph.D. Scholar) Mahatma Gandhi Nursing College (MGUMST), Sitapura, Jaipur

Corresponding Email: soni80giriraj@gmail.com, omprakash2030@yahoo.in

\begin{abstract}
Currently use of mobile phone in our society increased day by day. Many benefit of mobile phone but on the other hand excessive use of mobile phone become problematic in nature. In this time use of mobile phone increased concern in our society and in this regards great efforts have been made through research to identify problematic use of mobile phone.
\end{abstract}

Keyword: Mobile Phone, Uses, Effects, Mental Health.

\begin{tabular}{ccc}
\hline Received & Accepted & Available online \\
\hline $24 / 04 / 2021$ & $28 / 04 / 2021$ & $05 / 05 / 2021$ \\
\hline
\end{tabular}

\section{INTRODUCTION}

In technological advancement increasing mental distress and treatment for mental health conditions also increased due to more use of mobile phone. Inpatient hospital admissions for mental health illness increased substantially. Data show that presentations to hospital for suicidal attempts doubled between 2008 and 2015, with the increasing attempts in girls.

Person who has a mobile phone has reached $89 \%$, more than doubling over a 6 -year period; moreover, more than $70 \%$ use social media per day. Analysis found that $86 \%$ of students have mobile phone with increased use of social media communication with their growing age. Its evidence that due to

mobile phone and social media use with mental distress and suicide occurs.

More social media interaction also frequently occurs than in person interact with other people An survey of middleand high school students revealed that the increase number of suicidal thought and ideas higher among those who had more cyber uses.

\section{EFFECTS OF SMARTPHONES ON MENTAL HEALTH}

An observational study find spending more than a few hours per week using electronic 


\section{SDES-International Journal of Interdisciplinary Research \\ (Peer Reviewed Refereed Journal) \\ Crossref DOI: 10.47997/SDES-IJIR/02-02-2021 \\ https://shreedadueducational.com/iournal}

ISSN (0): 2582:7162

media correlated negatively with selfreported happiness or time spent on nonscreen activities correlated positively with psychological well-being. Other observational studies have shown that spending more than 2 hours a per day on social networking sites and mobile phone with high rates of suicidality and depressive symptoms in the girls although all individual try to protect mental illness and negative symptoms.

Individuals increasingly interact online rather than in person. A recent study using experience sampling in 304 participants find that even the available of phones on a table caused participants who were randomly assigned to that condition to feel more diverted and also have lack of happiness during social interactions compared with those who were putting their phone away from his reach. Phone use was also found to predict distraction, which in turn predicted greater boredom and worse overall the person mood.

\section{SLEEP-LOSS \& ITS SOCIAL MEDIA} AFFECT

An analysis found a sudden increase in the proportion of getting insufficient sleep after
2011-2013, with more than $40 \%$ sleeping less than 7 hours most nights in 2015 .

This is also indicated that using mobile phone more than $2 \mathrm{hrs}$ a day may lead to sleep disturbances or inadequate sleep. Relationship found that using mobile phone more than 1 hrs per day also responsible for lack of sleep.

Individual's using mobile screen before bedtime was shown to disturbed sleeps. Longer time to fall asleep and decreased evening sleepiness, reduced melatonin secretion, circadian clock delay, diminished amount and lack of eye movement and lack of alertness in early morning.

Association between portable screen-based media devices and sleep outcomes found that use of media at bedtime was associated with diminished sleep time and good quality of sleep. Person using portable screen in the bedroom was associate to disturbed sleep and more possibility to check mobile phone screen more and more in the frequent ways or owing to a conditioned response involving increased arousal. Data from a 1101 adolescents in Australia showed that lack of sleep related to use of mobile phone 


\section{SDES-International Journal of Interdisciplinary Research}

(Peer Reviewed Refereed Journal)

ISSN (0): 2582:7162

Crossref DOI: 10.47997/SDES-IJIR/02-02-2021

https://shreedadueducational.com/journal

at night leads to depressed mood and also develop low level of self esteem.

INDIVIDUALS DIFFERENCES MORE SUSCEPTIBLE TO MENTAL HEALTH

\section{EFFECTS}

Population-based studies suggest a association between social media use and mental illness among peoples. The impact of these technologies may vary among individuals to individual and some may be less susceptible to harm. Girls and young women tend to spend more time on social media than boys do, have more exposure to cyber persecute and show tendency to experience more mental health consequences which is continuously with recent times and epidemiologic trends indicating depressive symptoms, self-harm and suicidality have increased among young females in particular. It also found that passive use of face book had a negative effect on mood on the other hand active use had a positive impact on perceived online social support, which in turn had a positive impact on mood. A systematic review of 70 studies found that while social media use was correlated with depression, anxiety and measures of well-being, effects depends on the individual use of mobile phone \& how you interact.

Those individual that involve in rumination and brooding appeared to exacerbate negative effects of social media.

\section{HOW MIGHT PHYSICIANS USE THIS EVIDENCE TO INFORM THEIR PRACTICE:}

Despite the limitations of the evidence base at this time, clinicians or psychiatrist may be able to use currently available knowledge in the treatment and behaviour changes in mentally ill person. Psychiatrist treating with mental illness and those at risk of mental illness can discuss with patients and their families the known risks of social media and smartphone use to mental health. Clinical expert may choose to supporter for a harm reduction approach, suggesting reduced use of social media and the Internet rather than abstinence for youth, given evidence that suggests prolonged use is associated with poorer mental health.

\section{CONCLUSION}

Excessive use of mobile phone \& social media harm the individual's psychological health and we should follow the approach to diminish or cut down the excessive use of 


\section{SDES-International Journal of Interdisciplinary Research}

(Peer Reviewed Refereed Journal)

ISSN (0): 2582:7162

Crossref DOI: 10.47997/SDES-IJIR/02-02-2021

https://shreedadueducational.com/iournal

mobile phones. The American Academy of Pediatrics suggests that online relationships are part of typical adolescent development. For adolescents today, who have not known a world without social media, digital use are the rules and regulation. However, today's youth could benefit from proven individual and systemic interventions to help them navigate the challenges brought about by use of smartphones and social media, protect themselves from harm and use social media in a manner that safeguards their mental health, against a background of policy initiatives aimed at addressing the social, environmental and economic factors that underpin family well-being and nurture youth resilience.

Excessive use of mobile phone evolving public health concern that requires more study to identified the association between helpful and harmful technology use. Policy guidance is needed to outline harm reduction strategies in the organization for better development and reduce harms to employee.

\section{REFERENCES}

i. Smartphones, social media use and youth mental health (cmaj.ca)

ii. https://www.verywellmind.com/how-dosmartphones-affect-the-brain-2794892

iii. https://bmcpsychiatry.biomedcentral.co $\mathrm{m} /$ articles/10.1186/s12888-019-2350-x

iv. Bethany Harris, Timothy Regan, Jordan Schueler and Sherecce A. Fields:Problematic Mobile Phone and Smartphone Use Scales: A Systematic Review: Front. Psychol., 05 May 2020

v. Michael Bauer, Tasha Glenn, John Geddes: Smartphones in mental health: a critical review of back ground issues, current status and future concerns International Journal of Bipolar Disorders volume 8, Article number : $2(2020)$ 